\title{
The Systematic Review Data Repository (SRDR): descriptive characteristics of publicly available data and opportunities for research
}

\author{
Ian J. Saldanha ${ }^{1,2^{*}}$ D, Bryant T. Smith , Evangelia Ntzani ${ }^{1,3}$, Jens Jap ${ }^{1}$, Ethan M. Balk ${ }^{1}$ and Joseph Lau ${ }^{1}$
}

\begin{abstract}
Background: Conducting systematic reviews ("reviews") requires a great deal of effort and resources. Making data extracted during reviews available publicly could offer many benefits, including reducing unnecessary duplication of effort, standardizing data, supporting analyses to address secondary research questions, and facilitating methodologic research. Funded by the US Agency for Healthcare Research and Quality (AHRQ), the Systematic Review Data Repository (SRDR) is a free, web-based, open-source, data management and archival platform for reviews. Our specific objectives in this paper are to describe (1) the current extent of usage of SRDR and (2) the characteristics of all projects with publicly available data on the SRDR website.
\end{abstract}

Methods: We examined all projects with data made publicly available through SRDR as of November 12, 2019. We extracted information about the characteristics of these projects. Two investigators extracted and verified the data.

Results: SRDR has had 2552 individual user accounts belonging to users from 80 countries. Since SRDR's launch in 2012, data have been made available publicly for 152 of the 735 projects in SRDR (21\%), at a rate of 24.5 projects per year, on average. Most projects are in clinical fields (144/152 projects; 95\%); most have evaluated interventions (therapeutic or preventive) (109/152; 72\%). The most frequent health areas addressed are mental and behavioral disorders $(31 / 152 ; 20 \%)$ and diseases of the eye and ocular adnexa (23/152; 15\%). Two-thirds of the projects (104/ $152 ; 67 \%)$ were funded by $A H R Q$, and one-sixth (23/152; 15\%) are Cochrane reviews. The 152 projects each address a median of 3 research questions (IQR 1-5) and include a median of 70 studies (IQR 20-130).

Conclusions: Until we arrive at a future in which the systematic review and broader research communities are comfortable with the accuracy of automated data extraction, re-use of data extracted by humans has the potential to help reduce redundancy and costs. The 152 projects with publicly available data through SRDR, and the more than 15,000 studies therein, are freely available to researchers and the general public who might be working on similar reviews or updates of reviews or who want access to the data for decision-making, meta-research, or other purposes.

\footnotetext{
* Correspondence: ian_saldanha@brown.edu

'Department of Health Services, Policy, and Practice, Center for Evidence Synthesis in Health, Brown University School of Public Health, 121 South Main Street, Box G-S121-8, Providence, RI 02903, USA

2Department of Epidemiology, Center for Evidence Synthesis in Health,

Brown University School of Public Health, 121 South Main Street, Box

G-S121-8, Providence, RI 02903, USA

Full list of author information is available at the end of the article
}

(c) The Author(s). 2019 Open Access This article is distributed under the terms of the Creative Commons Attribution 4.0 International License (http://creativecommons.org/licenses/by/4.0/), which permits unrestricted use, distribution, and reproduction in any medium, provided you give appropriate credit to the original author(s) and the source, provide a link to the Creative Commons license, and indicate if changes were made. The Creative Commons Public Domain Dedication waiver (http://creativecommons.org/publicdomain/zero/1.0/) applies to the data made available in this article, unless otherwise stated. 


\section{Background}

Conducting systematic reviews requires a great deal of effort and resources to gather, organize, analyze, and interpret large amounts of information about included studies [1]. Increasingly, systematic reviewers look beyond traditional reports of studies (i.e., journal articles) and incorporate information from multiple sources, such as study registries, clinical study reports, conference abstracts, and communications with study authors $[2,3]$. Making all data extracted during systematic reviews publicly available could offer many benefits, including reducing unnecessary duplication of effort, standardizing data, supporting analyses to address secondary research questions, and facilitating methodologic research related to both primary studies and systematic reviews ("metaresearch," i.e., methodologic and other types of research on research [4]) [5]. Examples of meta-research include research that has examined the empirical evidence for the impact of methodologic aspects of studies, such as allocation concealment [6] and outcome reporting [7].

To realize the potential benefits of public access to extracted study data from systematic reviews, we need infrastructure that supports such access. One platform for making systematic review data publicly available is the Systematic Review Data Repository (SRDR). Launched in 2012, SRDR (recently updated to SRDR+, available at https://srdrplus.ahrq.gov) is a free, Web-based, opensource, data management and archival platform for systematic reviews $[8,9]$. SRDR is a relational database that allows the creation of flexible data extraction forms for structured data collection and risk of bias assessment. We, at the Brown University Evidence-based Practice Center (EPC), developed and are continuing the advancement and management of SRDR. SRDR, started by the Tufts Medical Center EPC, has been continually funded by the US Agency for Healthcare Research and Quality (AHRQ).

SRDR includes projects related to systematic reviews of any topic in any field, regardless of whether the review's focus is on interventions, diagnosis, epidemiology, methodology, other topics, or indeed non-health-related research. The research team working on a given project in SRDR can request that the data be made available publicly. Publication is typically requested after completion of a project, but can be done even prior to completion, in which case the data that the research team changes subsequent to publication are updated on the SRDR published projects website automatically and instantly. The SRDR Management Team at the Brown EPC approves all requests for making SRDR project data public and manages the website that hosts the publicly available data (https://srdr.ahrq.gov/projects/published).

While SRDR is in part designed for data extraction, organization, and tabulation during systematic reviews, in this paper, we focus on its archival functionality. SRDR facilitates global collaboration and serves as a repository for archiving and sharing structured systematic review data for easy reuse, such as during systematic review updates or conduct of systematic reviews on closely related topics. Now in operation for 7 years, SRDR has accumulated a rich corpus of systematic review projects that have addressed a range of topics; a sizeable proportion of these systematic reviews have been funded by AHRQ or have been conducted by other groups that use SRDR frequently. AHRQ requires EPCs to make the data extracted during systematic reviews publicly available through SRDR.

To our knowledge, the projects in SRDR that have made their data public have not been systematically characterized. Such a characterization could help spread awareness about the contents of this resource and, thereby, help realize the potential benefits of public access to study data extracted during systematic reviews. Our specific objectives in this paper are to describe (1) the current extent of usage of SRDR and (2) the characteristics of all projects with publicly-available data on the SRDR website.

\section{Methods \\ SRDR user and project statistics}

On November 12, 2019, we ran custom MySQL queries on the SRDR database to gather descriptive statistics regarding SRDR users, projects, and website visits. A "user" is defined as a unique SRDR username and email address. A "project" is defined as a collaborative or individual enterprise among users within SRDR; a project may or may not be a systematic review. A user may have either a "public commentator account" or a "project contributor account." The former type of account allows users only the ability to make comments on existing projects in SRDR. The latter type of account allows users to also create new projects and contribute modifications to existing SRDR projects in which they are participating. A "session" is defined as a unique visit from a user to the SRDR website; during a session, a user may open multiple projects and/or multiple pages within a project in SRDR. A "page" in SRDR is a webpage within the SRDR system.

\section{Information extracted about projects with publicly available data}

For this analysis, we examined all projects with data made available publicly through SRDR as of November 12, 2019. We extracted the following information pertaining to each project:

- Year project was initiated in SRDR, 
- Year project data were made available on the SRDR website,

- Discipline (clinical; public health; education; ecology; other),

- Primary focus of the project (interventions; diagnosis; epidemiology [exposure-outcome relationships]; epidemiology [incidence or prevalence]; methodology)-more than one option may have applied to a project,

- Primary health area addressed (mapped to International Classification of Diseases-10 [10]),

- Type of project (full systematic review; technical brief; evidence map; methods research; other) - systematic reviews and technical briefs were distinguished if the project's record distinguished them,

- Whether the project was an AHRQ-funded EPC project, a Cochrane review, or neither,

- Whether the systematic review was registered in PROSPERO (an online registry of systematic review protocols; available at https://www.crd.york.ac.uk/ prospero/),

- Whether the systematic review was an update of a previous systematic review (determined if the title or description of the project explicitly stated the review was an update, or if the titles of two reviews were the same/similar and we were otherwise aware of one being an update),

- Funding source for the project,

- Country of the corresponding author,

- Number of research questions (referred to as "Key Questions" in AHRQ-funded reviews),

- Number of included studies, and

- Format(s) in which included study data were added to SRDR. There are three possible formats: (1) manual completion of SRDR data extraction forms; (2) import of data into SRDR data extraction forms; and (3) upload of data as flat files (e.g., Microsoft ${ }^{\circ}$ Excel, Adobe ${ }^{\circ} \mathrm{PDF}$ ) directly to the project (i.e., without use of SRDR data extraction forms). A given project may have added data in more than one of these possible formats. Either manual completion or importing of data into SRDR data extraction forms results in data that are structured; uploading of data results in flat files.

Regarding registration in PROSPERO, if registration status was not provided on the "Published Projects" page of the SRDR website, we examined any available full report of the systematic review. We obtained full reports of AHRQ-funded systematic reviews from the AHRQ Website (https://www.ahrq. gov/research/findings/evidence-based-reports/index.

html), Cochrane systematic reviews from the
Cochrane Library (https://www.cochranelibrary.com), and other systematic reviews from journal articles. If PROSPERO registration status was not provided in the full report, we searched the PROSPERO registry (https://www. crd.york.ac.uk/prospero/\#searchadvanced) using keywords from the title of the project. If these efforts did not yield a PROSPERO record for the systematic review, we considered it to be not registered in PROSPERO. Of note, PROSPERO does not allow registration of scoping reviews. Therefore, we did not examine PROSPERO registration status for technical briefs, evidence maps, and methods research.

\section{Data extraction process}

We used SRDR to develop a standardized data extraction form that included 22 items (form available at https://bit.ly/2VhR7DU; and data from this project are available publicly at https://srdr.ahrq.gov/projects/published). Two investigators extracted and verified data (BTS and IJS). For each project, one investigator extracted all information and a second verified the data. All discrepancies were resolved through discussion.

Of note, when more than one project pertained to the same systematic review, we counted them as separate projects. Also, for each project, we extracted all information from SRDR (except for PROSPERO registration); we did not examine any available systematic review protocols, associated journal articles, or other external sources of information. As such, the information presented in this paper reflects the information in SRDR and not necessarily what might be reported elsewhere for a given systematic review.

\section{Statistical analyses}

We analyzed frequencies and percentages for categorical items and medians and interquartile ranges (IQRs) for continuous items. We compared categorical items descriptively. We performed Kruskal-Wallis tests for hypothesis testing of differences between medians of continuous items. We performed all analyses using Stata $^{\bullet}$ version 16 (College Station, Texas, USA).

\section{Results}

\section{SRDR user and project statistics}

As of November 12, 2019, SRDR has had 2552 individual user accounts belonging to users from 80 countries. These include 1407 project contributor accounts from 53 countries; the remaining accounts are public commentator accounts. Countries with the most project contributor accounts are the USA, Canada, the UK, and Greece. From January 1 to November 12, 2019, the SRDR website had an average of 84 sessions per day and 70 visitors per day; each visitor visited approximately 4.6 pages per session. All 
told users have created 735 projects in SRDR, with a median of three collaborators per project (range 1 to 54). The total number of studies across all these 735 projects is 90,142 .

\section{Statistics related to projects with publicly available data}

We found that data are available publicly for 152 of the 735 projects in SRDR (21\%). Considering full years since the 2012 launch of SRDR (i.e., 2013 to 2018), data from 25.3 projects per year, on average, have been made available publicly through SRDR (Fig. 1). The median time from project initiation in SRDR to public availability of the data through SRDR was 4 months (IQR 1 to 14). Note that this does not include the time spent on the systematic review steps before data extraction (e.g., question formulation, abstract screening) that have traditionally occurred outside SRDR.

The 152 published projects pertain to 148 distinct systematic reviews. One review was associated with four projects and another review was associated with two projects; in both instances, the multiple projects pertained to separate research questions of the same review. Three reviews each included one or more updated reviews, corresponding to seven SRDR projects. Because each update involved non-trivial changes to the research questions, we considered these seven projects as seven separate systematic reviews. In this paper, we consider projects as the unit of analysis. All told, the 152 projects include data from 15,621 studies (not accounting for overlap of some studies between projects).

\section{Descriptive characteristics of projects with publicly available data}

Most of the published projects are in clinical fields (144/ 152 projects; 95\%); the remainder are in public health (6/152 projects; $4 \%)$ or toxicology (2/152 projects; $1 \%)$ (Table 1). The primary focus of most projects is either interventions (therapeutic or preventive) (109/152 projects; $72 \%)$ or diagnosis (15/152 projects; $10 \%)$. The projects address a range of health areas. The most frequent health area addressed is mental and behavioral disorders (31/152 projects; 20\%); the next most frequent is diseases of the eye and ocular adnexa (23/152 projects; 15\%). For comparison, the most frequent health areas addressed in the 588 projects without publicly available data are diseases of the eye and ocular adnexa (85/588 projects; $15 \%)$; endocrine, nutritional, and metabolic diseases (50/588 projects; $9 \%)$; and neoplasms (37/588 projects; 6\%). Appendix lists the specific topics addressed in all 152 projects with publicly available data, by health area.

Most projects are full systematic reviews (132/152 projects; $87 \%)$. Fewer than half of these (48/117 projects; 44\%) were registered in PROSPERO. Among all 152 projects, most (91\%) were funded by government sources and $95 \%$ have a US-based corresponding author. The data in almost two-thirds of all projects (94/152 projects; $62 \%)$ are structured, while the remainder are in flat files (58/152 projects; $38 \%)$.

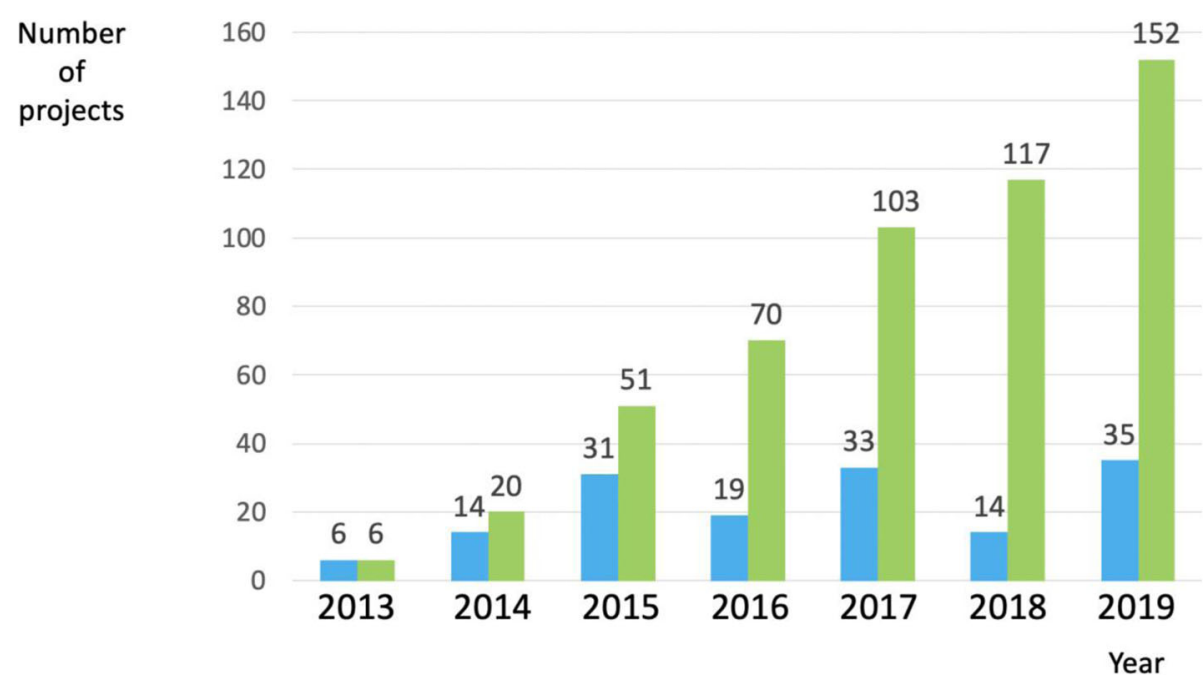

Fig. 1 Annual and cumulative numbers of projects with publicly available data on the Systematic Review Data Repository (SRDR) website since the year after SRDR's inception in 2012 (i.e., 2013 to 2019). Note: Data for 2019 only includes January 1, 2019 to November 12, 2019. The spike in the number of projects in 2019, although it includes data from only approximately 10.5 months is because we recently reached out to leads of all existing projects in SRDR to encourage them to make the project data available publicly. Blue bars =annual number of projects. Green bars $=$ cumulative number of projects 
Table 1 Projects with data available publicly on the Systematic Review Data Repository (SRDR) website as of November 12, 2019, sorted by whether or not the review was funded by the Agency for Healthcare Research and Quality (AHRQ)

\begin{tabular}{|c|c|c|c|c|c|c|}
\hline \multirow[t]{2}{*}{ Characteristic } & \multicolumn{2}{|c|}{$\begin{array}{l}\text { Projects funded by } \\
\text { AHRQ }(N=104)\end{array}$} & \multicolumn{2}{|c|}{$\begin{array}{l}\text { Projects not funded } \\
\text { by AHRQ }(N=48)\end{array}$} & \multicolumn{2}{|c|}{$\begin{array}{l}\text { All projects } \\
(N=152)\end{array}$} \\
\hline & $\bar{N}$ & $\%$ & $\bar{N}$ & $\%$ & $\bar{N}$ & $\%$ \\
\hline \multicolumn{7}{|l|}{ Discipline } \\
\hline Clinical & 97 & (93) & 47 & $(98)$ & 144 & (95) \\
\hline Public health & 5 & $(5)$ & 1 & $(2)$ & 6 & (4) \\
\hline Toxicology & 2 & $(2)$ & 0 & $(0)$ & 2 & (1) \\
\hline \multicolumn{7}{|l|}{ Primary focus of the review } \\
\hline Interventions (therapeutic or preventive) & 79 & $(76)$ & 30 & $(63)$ & 109 & (72) \\
\hline Diagnosis & 14 & $(14)$ & 1 & $(2)$ & 15 & (10) \\
\hline Epidemiology_exposure-outcome association & 0 & $(0)$ & 10 & $(21)$ & 10 & (7) \\
\hline Epidemiology_incidence or prevalence & 2 & $(2)$ & 2 & (4) & 4 & (3) \\
\hline Prognosis & 1 & $(1)$ & 0 & $(0)$ & 1 & (1) \\
\hline Screening & 6 & $(6)$ & 0 & $(0)$ & 6 & (4) \\
\hline Methodology & 2 & $(2)$ & 5 & $(10)$ & 7 & (5) \\
\hline \multicolumn{7}{|l|}{ Primary health area addressed (per International Classification of Diseases-10) } \\
\hline Mental and behavioral disorders & 30 & $(29)$ & 1 & $(2)$ & 31 & (20) \\
\hline Diseases of the eye and ocular adnexa & 1 & $(1)$ & 22 & $(46)$ & 23 & (15) \\
\hline Neoplasms & 11 & $(11)$ & 2 & (4) & 13 & (9) \\
\hline Diseases of the musculoskeletal system and connective tissue & 11 & $(11)$ & 1 & $(2)$ & 12 & (8) \\
\hline Symptoms, signs, and abnormal clinical and laboratory findings, not elsewhere classified & 4 & $(4)$ & 6 & $(13)$ & 10 & (7) \\
\hline Diseases of the genitourinary system & 5 & $(5)$ & 4 & $(8)$ & 9 & (6) \\
\hline Diseases of the circulatory system & 7 & $(7)$ & 1 & $(2)$ & 8 & (5) \\
\hline Diseases of the respiratory system & 7 & $(7)$ & 0 & $(0)$ & 7 & $(5)$ \\
\hline Certain infectious and parasitic diseases & 7 & $(7)$ & 0 & $(0)$ & 7 & $(5)$ \\
\hline Factors influencing health status and contact with health services & 5 & $(5)$ & 1 & $(2)$ & 6 & (4) \\
\hline Injury, poisoning, and certain other consequences of external causes & 5 & $(5)$ & 0 & $(0)$ & 5 & (3) \\
\hline Endocrine, nutritional, and metabolic diseases & 2 & $(2)$ & 2 & (4) & 4 & (3) \\
\hline Pregnancy, childbirth, and the puerperium & 3 & (3) & 1 & $(2)$ & 4 & (3) \\
\hline Diseases of the digestive system & 2 & $(2)$ & 1 & $(2)$ & 3 & $(2)$ \\
\hline Congenital malformations, deformations, and chromosomal abnormalities & 1 & $(1)$ & 0 & $(0)$ & 1 & $(1)$ \\
\hline Diseases of the ear and mastoid process & 1 & $(1)$ & 0 & $(0)$ & 1 & $(1)$ \\
\hline Codes for special purposes & 0 & $(0)$ & 1 & $(2)$ & 1 & $(1)$ \\
\hline Other-methodology & 2 & $(2)$ & 5 & $(10)$ & 7 & (5) \\
\hline \multicolumn{7}{|l|}{ Type of project } \\
\hline Full systematic review/technology assessment & 93 & $(90)$ & 39 & $(81)$ & 132 & $(87)$ \\
\hline Technical brief & 8 & (8) & 0 & $(0)$ & 8 & $(5)$ \\
\hline Methods research & 2 & $(2)$ & 5 & $(10)$ & 7 & (5) \\
\hline Evidence map & 1 & $(1)$ & 4 & $(8)$ & 5 & (3) \\
\hline \multicolumn{7}{|l|}{ Registration status in PROSPERO (for full systematic reviews/technology assessments only) } \\
\hline Yes & 46 & $(49)$ & 12 & $(31)$ & 48 & $(44)$ \\
\hline No & 47 & $(51)$ & 27 & $(69)$ & 74 & $(56)$ \\
\hline \multicolumn{7}{|l|}{ Funding source(s) for project (more than one funding source could apply) } \\
\hline Government & 104 & $(100)$ & 32 & $(70)$ & 136 & $(91)$ \\
\hline Pharmaceutical industry & 0 & (0) & 0 & (0) & 0 & (0) \\
\hline
\end{tabular}


Table 1 Projects with data available publicly on the Systematic Review Data Repository (SRDR) website as of November 12, 2019, sorted by whether or not the review was funded by the Agency for Healthcare Research and Quality (AHRQ) (Continued)

\begin{tabular}{|c|c|c|c|c|c|c|}
\hline \multirow[t]{2}{*}{ Characteristic } & \multicolumn{2}{|c|}{$\begin{array}{l}\text { Projects funded by } \\
\text { AHRQ }(N=104)\end{array}$} & \multicolumn{2}{|c|}{$\begin{array}{l}\text { Projects not funded } \\
\text { by AHRQ }(N=48)\end{array}$} & \multicolumn{2}{|c|}{$\begin{array}{l}\text { All projects } \\
(N=152)\end{array}$} \\
\hline & $\bar{N}$ & $\%$ & $\bar{N}$ & $\%$ & $\bar{N}$ & $\%$ \\
\hline Other industry & 0 & $(0)$ & 5 & $(11)$ & 5 & (3) \\
\hline Foundation/professional society & 0 & $(0)$ & 3 & (7) & 3 & (2) \\
\hline Other funding source & 0 & $(0)$ & 11 & $(24)$ & 11 & (7) \\
\hline Explicitly stated that no funding was received & 0 & $(0)$ & 2 & (5) & 2 & (2) \\
\hline \multicolumn{7}{|l|}{ Country of corresponding author } \\
\hline USA & 102 & (98) & 43 & $(90)$ & 145 & (95) \\
\hline Canada & 2 & $(2)$ & 0 & $(0)$ & 2 & (1) \\
\hline UK & 0 & (0) & 2 & (4) & 2 & (1) \\
\hline Germany & 0 & (0) & 1 & $(2)$ & 1 & (1) \\
\hline Lebanon & 0 & (0) & 1 & $(2)$ & 1 & (1) \\
\hline Saudi Arabia & 0 & (0) & 1 & (2) & 1 & (1) \\
\hline \multicolumn{7}{|c|}{ Format of addition of included study data to SRDR (more than one format could apply) } \\
\hline Manual completion of SRDR data extraction forms & 27 & $(26)$ & 39 & $(81)$ & 66 & (43) \\
\hline Import of data into SRDR data extraction forms & 23 & $(22)$ & 19 & $(40)$ & 42 & (28) \\
\hline Upload of data as flat files (i.e., not into SRDR data extraction forms) & 68 & $(65)$ & 2 & (4) & 70 & (46) \\
\hline
\end{tabular}

\section{Comparison between characteristics of AHRQ-funded and non-AHRQ-funded projects with publicly available data} About two-thirds of the projects (104/152; 68\%) were funded by AHRQ. There are some notable differences between projects funded by AHRQ and those that were not (Table 1). Approximately one in five non-AHRQ-funded projects (21\%) focus on exposure-outcome relationships, while none of the AHRQ-funded projects do. Almost 3 in 10 AHRQfunded projects (29\%) focus on mental and behavioral disorders, while only $2 \%$ of the non-AHRQfunded projects do. Instead, almost half of the nonAHRQ-funded projects (46\%) focus on diseases of the eye and ocular adnexa, largely due to the fact that Cochrane Eyes and Vision, based in London, UK, with a Satellite in Baltimore, Maryland, USA, has been encouraging its systematic review authors to use SRDR for data extraction. While all AHRQfunded projects were government-funded, 3 in 10 non-AHRQ-funded projects (30\%) were funded by non-government sources. Almost half of the nonAHRQ-funded projects $(23 / 48 ; 48 \%)$ are Cochrane systematic reviews.

Overall, the 152 projects address a median of three research questions each (IQR 1-5) (Table 2). AHRQfunded projects address a considerably higher number of research questions than non-AHRQ-funded projects (median 4 vs. 1 ; $P=0.0001$ ). Overall, the 152 projects include a median of 70 studies each (IQR 20-130). AHRQ-funded projects include more than six times as many studies as non-AHRQ-funded projects (median 84 vs. $13.5 ; P=0.0001)$.

Table 2 Numbers of research questions and included studies in projects with data available publicly on the Systematic Review Data Repository (SRDR) website as of November 12, 2019, sorted by whether or not the review was funded by the Agency for Healthcare Research and Quality (AHRQ)

\begin{tabular}{|c|c|c|c|}
\hline Characteristic & Projects funded by AHRQ $(N=104)$ & Projects not funded by AHRQ $(N=48)$ & All projects $(N=152)$ \\
\hline \multicolumn{4}{|c|}{ Number of research questions per project } \\
\hline Median (interquartile range) & 4 (3 to 6$)$ & $1(1$ to 1$)$ & $3(1$ to 5$)$ \\
\hline Range & 1 to 15 & 1 to 5 & 1 to 15 \\
\hline \multicolumn{4}{|c|}{ Number of included studies per project ${ }^{a}$} \\
\hline Median (interquartile range) & 84 (36 to 139$)$ & 13.5 (3 to 58$)$ & 70 (20 to 130$)$ \\
\hline Range & 0 to 281 & 1 to 2013 & (0 to 2013) \\
\hline
\end{tabular}

${ }^{a}$ Excludes three projects that examined systematic reviews only (i.e., did not examine primary studies) 


\section{Discussion}

Since its inception in 2012, SRDR has accumulated a corpus of 152 systematic review projects with publicly available data from more than 15,000 studies. Data from these projects and studies can be accessed by anyone around the world to review, re-use in a new systematic review or related research project, conduct methodologic research, or otherwise use for various purposes. Almost two-thirds of these projects include data in a structured format. A majority of the 152 projects are in clinical fields, focus on interventions or diagnosis, and are funded by government sources. The projects cover various health areas, with mental and behavioral disorders and diseases of the eye and ocular adnexa being the most common.

\section{Comparison with other investigations}

There are some interesting differences between the findings of this investigation and others that have examined the characteristics of systematic reviews in health. For example, others have found that about half of systematic reviews have focused on interventions and that about $45 \%$ have been funded by government sources $[11,12]$. In SRDR, $72 \%$ of publicly available reviews focused on interventions and $91 \%$ were funded by government sources. These higher proportions in SRDR are largely driven by the large proportion of reviews in it that have been funded by AHRQ (68\%) or are Cochrane systematic reviews (15\%). AHRQ-funded and Cochrane systematic reviews tend to focus more on interventions than do other systematic reviews. Similarly, another investigation found that the median number of included studies per systematic review was 15 [11], whereas the median number of studies per review in SRDR is 70 . This difference is also largely driven by the predominance of AHRQ-funded reviews, which tend to be broader in scope and address more research questions than non-AHRQ-funded systematic reviews. Indeed, in SRDR, the median number of research questions per AHRQ-funded review is approximately eight times that of non-AHRQ-funded reviews.

Our finding that $44 \%$ of eligible systematic reviews were registered in PROSPERO is a considerable improvement from the $4 \%$ that was reported in a random sample of 300 systematic reviews published in 2014 [11]. However, since AHRQ and Cochrane strongly encourage PROSPERO registration, we would expect reviews in SRDR to be more likely to have registered protocols than other systematic reviews. While the higher percentage is a good sign, we urge all systematic review teams to register their systematic reviews prospectively in PROSPERO. Prospective registration offers many benefits, such as promoting transparency, reducing the potential for bias, and reducing the potential for redundancy [13,
14]. Additionally, in light of the growing numbers of abridged types of evidence syntheses, such as evidence maps/scoping reviews [15], living systematic reviews [16], and rapid reviews/technical briefs [17], we agree with Page et al. [12] that the PROSPERO registry should expand its eligibility criteria to include these other types of reviews.

Potential value of publicly available data from systematic reviews to the global community

To our knowledge, SRDR is one of a kind. It serves as a free, online, data management platform for collaboration among members of a systematic review team [8]. SRDR also offers free, open access to data about primary studies that have been extracted for systematic and other reviews on a range of topics. In this way, SRDR helps advance the open-access movement in science. We agree, however, with current guidance that those reusing shared data should cite the original data source (i.e., the systematic review and the SRDR platform from which the data were obtained) $[5,18]$. To facilitate such citing, we provide each publicly available project in SRDR with an associated digital object identifier (DOI) for easy and persistent online identification.

The past decade has witnessed an almost threefold surge in the number of systematic reviews [11]. While some of these systematic reviews have been demonstrated to be redundant [19], conducting new systematic reviews on topics related to existing systematic reviews is often required. For example, an update to an existing systematic review may be needed if it is out of date and/ or new studies are available. Other common scenarios that lead to a new systematic review being needed are when the eligibility criteria of an existing related systematic review were too narrow, a new type of intervention or comparator has emerged, or a broader search is needed [20]. In each of these and other related scenarios, a considerable amount of time and resources can be saved by using previously extracted data, where relevant. SRDR can help fulfill this need [8].

Efforts have been underway to begin strides towards a future in which data extraction for systematic reviews might be accurately and efficiently conducted using automation technologies [21-23]. In that context, while archival of data would still serve the purpose of transparency, re-use of data might not be of much added value because technology would be able to conduct data extraction inexpensively. While such a "revolution in automation of systematic reviews" is on the horizon, we are not there yet [24]. Until we arrive at such a future, one in which the systematic review and broader research communities are comfortable with the accuracy of automated data extraction, re-use of data extracted by humans can help reduce redundancy and costs. 
There appears to be support for sharing systematic review data. A 2014 survey found that $83 \%$ of systematic reviewers affiliated with the Cochrane Individual Participant Data (IPD) Review Group supported it [25]. However, we acknowledge that there might be barriers to completely relying on previously extracted data, especially when the previous systematic review team is different from the team undertaking the new systematic review. There may be concerns about whether the set of items extracted from studies in the previous review is adequate and whether the data extracted are accurate. While SRDR does not guarantee the adequacy and accuracy of extracted data, these aspects can be assessed by systematic review teams, such as through examination of data from a random sample of the studies. Alternatively, systematic review teams may choose to use the previously extracted data as the initial extraction in an approach similar to single (de novo) data extraction and verification.

SRDR can serve as a valuable platform for conducting methodologic research. Examples of such research that has already been conducted using SRDR are the Data Abstraction Assistant (DAA) Trial (a randomized controlled trial that compared different data extraction approaches [26-28]) and the current study and the six other methodologic projects described in this paper [2934]. SRDR also can serve as a source of data for metaresearch (i.e., methodologic and other types of research on research [4]). For example, researchers might analyze the populations, interventions, comparators, outcomes, funding sources, and/or other factors across systematic reviews, either within or across health areas.

Accessing and downloading publicly available data from SRDR is relatively straightforward through the SRDR Published Projects Website (available at https:// srdr.ahrq.gov/projects/published). As the SRDR management team, we are happy to help and/or partner with researchers to do so (see author contact information).

\section{Limitations to publicly available data on SRDR}

While the SRDR management team encourages and helps systematic review teams to make their data public and manages the website, we do not monitor the accuracy or completeness of the data. Inaccuracies in publicly available data in SRDR occur due to errors in data extraction from reports of primary studies [35]. It is not uncommon for such errors to be corrected in the final versions of reported data (e.g., journal publications), but not in SRDR. Because SRDR is not yet a data analysis platform, systematic review teams might not be vigilant about retrospectively updating data in SRDR to fix errors that might have been detected during data cleaning or analysis after exporting the data outside SRDR to statistical software or other applications. Second, SRDR is an evolving platform that is striving to improve how best to archive systematic review data for easy re-use. For example, while SRDR offers structured data extraction forms and structured data entry, these features are not always fully taken advantage of; more than one-third of the projects in SRDR have simply uploaded data as flat files. We recently developed an improved mechanism through which systematic reviews can import data from flat files into forms in SRDR so that the data can be shared in a structured format [36]. Third, it should be acknowledged that data have been made available for only a quarter of all projects in SRDR. While we, as the SRDR management team, do not require teams of systematic reviewers to make their data available, we encourage them to do so as quickly as possible. We believe that the median time from SRDR project initiation (i.e., data extraction phase) to public availability of data of 4 months is satisfactory. While we do not track the direction, magnitude, or statistical significance of results of systematic reviews in SRDR, a recent study by other investigators has demonstrated that statistical significance of results is not associated with the duration from protocol registration in PROSPERO to journal publication (for non-Cochrane systematic reviews) [37].

It should be noted that, since 2015, AHRQ has required EPCs to make each of their AHRQ-funded review's data available publicly through SRDR upon completion of the review. For systematic reviewers working on non-AHRQfunded projects, there is less of an incentive to make data available publicly. We strongly agree with Wolfenden and colleagues that platforms, such as SRDR, that make systematic review data available publicly can help maximize returns on the significant investments that are made in the systematic review enterprise [5]. We urge more systematic review teams to make their data available publicly.

\section{Limitations to this study}

The characteristics of the systematic reviews reported in this study are not intended to be representative of all systematic reviews. As discussed, most of the systematic reviews are AHRQ-funded or Cochrane reviews, leading to a predominance of reviews addressing clinical fields, evaluating interventions, and including higher numbers of studies than has been demonstrated in cross-sections of systematic reviews in other investigations.

\section{Conclusions}

We have described the characteristics of 152 systematic review projects with data that are available publicly through SRDR. These projects, and the more than 15, 000 studies therein, are freely available to researchers and the general public who might be working on similar systematic reviews or updates of systematic reviews or who want access to the data for decision-making, metaresearch, or other purposes. 


\section{Appendix}

Table 3 Topics of the 152 projects with publicly available data on the Systematic Review Data Repository (SRDR) website as of November 12, 2019, categorized by health area

\begin{tabular}{ll}
\hline Health area (number of projects) & Topic \\
\hline $\begin{array}{l}\text { Mental and behavioral disorders } \\
\text { (31 projects) }\end{array}$ & $\begin{array}{l}\text { Adverse behavioral effects of } \\
\text { caffeine consumption }\end{array}$
\end{tabular}

Age-related cognitive decline, mild cognitive impairment, and clinical

Alzheimer's-type dementia

Aggressive behavior in psychiatric patients

Agitation and aggression in dementia

Antipsychotics for children and young adults

Anxiety in children

Attention deficit hyperactivity disorder (ADHD) in children and adolescents

Atypical antipsychotics

Autism spectrum disorder

Autism spectrum disorder

Autism spectrum disorder

Autism spectrum disorder

Binge-eating disorder

Bipolar disorder

Developmental disabilities, intellectual disability, and autism spectrum disorder

Disparities within serious mental illness

Disruptive behavior in children and adolescents

Insomnia disorder

Major depressive disorder

Major depressive disorder

Major depressive disorder

Major depressive disorder

Major depressive disorder in adults

Major depressive disorder in older adults

Management strategies to reduce psychiatric readmissions

Mental health care for children and adolescents

Opioid use disorder

Post-acute coronary syndrome depression

Posttraumatic stress disorder (PTSD)

Schizophrenia

Treatment-resistant depression
Table 3 Topics of the 152 projects with publicly available data on the Systematic Review Data Repository (SRDR) website as of November 12, 2019, categorized by health area (Continued)

\begin{tabular}{|c|c|}
\hline Health area (number of projects) & Topic \\
\hline \multirow{23}{*}{$\begin{array}{l}\text { Diseases of the eye and ocular } \\
\text { adnexa ( } 23 \text { projects) }\end{array}$} & Acanthamoeba keratitis \\
\hline & Active trachoma \\
\hline & Active trachoma \\
\hline & Bacterial keratitis \\
\hline & Cataract \\
\hline & Cataract and glaucoma \\
\hline & Central serous chorioretinopathy \\
\hline & Chronic angle closure glaucoma \\
\hline & Chronic non-infectious uveitis \\
\hline & Glaucoma \\
\hline & Glaucoma \\
\hline & Glaucoma \\
\hline & Glaucoma \\
\hline & Intermittent exotropia \\
\hline & $\begin{array}{l}\text { Neovascular age-related macular } \\
\text { degeneration }\end{array}$ \\
\hline & $\begin{array}{l}\text { Neovascular age-related macular } \\
\text { degeneration }\end{array}$ \\
\hline & Onchocerciasis \\
\hline & Optic neuritis \\
\hline & Pigmentary glaucoma \\
\hline & Primary congenital glaucoma \\
\hline & Retinal prostheses \\
\hline & Retinitis pigmentosa \\
\hline & Trachoma trichiasis \\
\hline \multirow[t]{13}{*}{ Neoplasms (13 projects) } & $\begin{array}{l}\text { Basal cell and squamous cell } \\
\text { carcinoma of the skin }\end{array}$ \\
\hline & Basal cell carcinoma \\
\hline & $\begin{array}{l}\text { Decision aids for cancer screening } \\
\text { and treatment }\end{array}$ \\
\hline & Hepatocellular carcinoma \\
\hline & Infantile hemangioma \\
\hline & $\begin{array}{l}\text { Lymphoma, colorectal cancer, and } \\
\text { head and neck cancer }\end{array}$ \\
\hline & Metastatic breast cancer \\
\hline & $\begin{array}{l}\text { Non-metastatic muscle-invasive } \\
\text { bladder cancer }\end{array}$ \\
\hline & $\begin{array}{l}\text { Non-muscle-invasive bladder } \\
\text { cancer }\end{array}$ \\
\hline & Pancreatic adenocarcinoma \\
\hline & Primary breast cancer \\
\hline & $\begin{array}{l}\text { Risk assessment, genetic } \\
\text { counseling, and genetic } \\
\text { testing for BRCA-related cancer } \\
\text { in women }\end{array}$ \\
\hline & Small cell lung cancer \\
\hline
\end{tabular}


Table 3 Topics of the 152 projects with publicly available data on the Systematic Review Data Repository (SRDR) website as of November 12, 2019, categorized by health area (Continued)

\begin{tabular}{|c|c|}
\hline Health area (number of projects) & Topic \\
\hline \multirow{12}{*}{$\begin{array}{l}\text { Diseases of the musculoskeletal } \\
\text { system and connective tissue (12 } \\
\text { projects) }\end{array}$} & Acute pain \\
\hline & $\begin{array}{l}\text { Adverse bone and calcium balance } \\
\text { effects of caffeine consumption }\end{array}$ \\
\hline & Chronic pain \\
\hline & Common hip fractures \\
\hline & Early rheumatoid arthritis \\
\hline & Fibromyalgia \\
\hline & $\begin{array}{l}\text { Fractures in men and women with } \\
\text { low bone density or osteoporosis }\end{array}$ \\
\hline & Low-back pain \\
\hline & Low-back pain \\
\hline & Lower limb prosthesis \\
\hline & Osteoporosis fracture prevention \\
\hline & $\begin{array}{l}\text { Primary and secondary } \\
\text { osteoarthritis of the knee }\end{array}$ \\
\hline \multirow{10}{*}{$\begin{array}{l}\text { Symptoms, signs, and abnormal } \\
\text { clinical and laboratory findings, not } \\
\text { elsewhere classified ( } 10 \text { projects) }\end{array}$} & $\begin{array}{l}\text { Acute adverse effects of caffeine } \\
\text { consumption }\end{array}$ \\
\hline & Dietary fiber and health \\
\hline & Dietary sugars and health \\
\hline & $\begin{array}{l}\text { Home-based primary care } \\
\text { interventions }\end{array}$ \\
\hline & Low calorie sweeteners \\
\hline & Low calorie sweeteners \\
\hline & Palliative care \\
\hline & Routine preoperative testing \\
\hline & Silicone gel breast implants \\
\hline & Total Worker Health ${ }^{\oplus}$ (TWH) \\
\hline
\end{tabular}

Diseases of the genitourinary system (9 projects)
Table 3 Topics of the 152 projects with publicly available data on the Systematic Review Data Repository (SRDR) website as of November 12, 2019, categorized by health area (Continued)

\begin{tabular}{|c|c|}
\hline Health area (number of projects) & Topic \\
\hline & $\begin{array}{l}\text { Stroke prevention in patients with } \\
\text { atrial fibrillation }\end{array}$ \\
\hline & $\begin{array}{l}\text { Venous thromboembolism } \\
\text { prophylaxis }\end{array}$ \\
\hline & $\begin{array}{l}\text { Venous thromboembolism } \\
\text { prophylaxis in orthopedic surgery }\end{array}$ \\
\hline \multirow{7}{*}{$\begin{array}{l}\text { Certain infectious and parasitic } \\
\text { diseases ( } 7 \text { projects) }\end{array}$} & Clostridium difficile infection \\
\hline & Clostridium difficile infection \\
\hline & Healthcare-associated infections \\
\hline & $\begin{array}{l}\text { Pre-exposure prophylaxis for } \\
\text { prevention of HIV infection }\end{array}$ \\
\hline & $\begin{array}{l}\text { Screening for hepatitis B virus } \\
\text { infection in pregnant women }\end{array}$ \\
\hline & $\begin{array}{l}\text { Screening for HIV infection in } \\
\text { asymptomatic, nonpregnant } \\
\text { adolescents and adults }\end{array}$ \\
\hline & $\begin{array}{l}\text { Screening for HIV infection in } \\
\text { pregnant women }\end{array}$ \\
\hline \multirow[t]{7}{*}{$\begin{array}{l}\text { Diseases of the respiratory system } \\
(7 \text { projects) }\end{array}$} & $\begin{array}{l}\text { Acute exacerbations of chronic } \\
\text { obstructive pulmonary disease } \\
\text { (COPD) in adults }\end{array}$ \\
\hline & Acute respiratory tract infections \\
\hline & Asthma \\
\hline & Asthma \\
\hline & Asthma \\
\hline & Asthma \\
\hline & $\begin{array}{l}\text { Obstructive sleep-disordered } \\
\text { breathing or recurrent throat } \\
\text { infection in children }\end{array}$ \\
\hline \multirow{6}{*}{$\begin{array}{l}\text { Factors influencing health status } \\
\text { and contact with health services ( } 6 \\
\text { projects) }\end{array}$} & Health disparities \\
\hline & Health information exchange \\
\hline & Health services \\
\hline & Safety in nursing home settings \\
\hline & Telehealth \\
\hline & Telehealth \\
\hline \multirow{5}{*}{$\begin{array}{l}\text { Injury, poisoning, and certain other } \\
\text { consequences of external causes } \\
\text { (5 projects) }\end{array}$} & Field triage of trauma \\
\hline & $\begin{array}{l}\text { Physiologic predictors of severe } \\
\text { injury }\end{array}$ \\
\hline & Suspected opioid overdose \\
\hline & $\begin{array}{l}\text { Screening for elevated blood lead } \\
\text { levels in children }\end{array}$ \\
\hline & $\begin{array}{l}\text { Screening for elevated blood lead } \\
\text { levels in pregnant women }\end{array}$ \\
\hline \multirow{4}{*}{$\begin{array}{l}\text { Endocrine, nutritional, and } \\
\text { metabolic diseases ( } 4 \text { projects) }\end{array}$} & Diabetes \\
\hline & Diabetes \\
\hline & Diabetes \\
\hline & Type 2 diabetes \\
\hline Pregnancy, childbirth, and the & Adverse reproductive and \\
\hline
\end{tabular}


Table 3 Topics of the 152 projects with publicly available data on the Systematic Review Data Repository (SRDR) website as of November 12, 2019, categorized by health area (Continued)

\begin{tabular}{|c|c|}
\hline Health area (number of projects) & Topic \\
\hline \multirow[t]{4}{*}{ puerperium (4 projects) } & $\begin{array}{l}\text { developmental effects } \\
\text { of caffeine } \\
\text { consumption }\end{array}$ \\
\hline & $\begin{array}{l}\text { Breastfeeding programs, policies, } \\
\text { uptake and maternal health } \\
\text { outcomes in developed countries }\end{array}$ \\
\hline & Gestational diabetes \\
\hline & Postpartum hemorrhage \\
\hline \multirow[t]{3}{*}{$\begin{array}{l}\text { Diseases of the digestive system ( } 3 \\
\text { projects) }\end{array}$} & $\begin{array}{l}\text { Bariatric surgery in the Medicare } \\
\text { population }\end{array}$ \\
\hline & Fecal incontinence \\
\hline & $\begin{array}{l}\text { Non-alcoholic fatty liver disease } \\
\text { (NAFLD) }\end{array}$ \\
\hline $\begin{array}{l}\text { Congenital malformations, } \\
\text { deformations, and chromosomal } \\
\text { abnormalities ( } 1 \text { project) }\end{array}$ & Ankyloglossia \\
\hline $\begin{array}{l}\text { Diseases of the ear and mastoid } \\
\text { process ( } 1 \text { project) }\end{array}$ & Tympanostomy tubes in children \\
\hline $\begin{array}{l}\text { Codes for special purposes ( } 1 \\
\text { project) }\end{array}$ & Privacy and genetic information \\
\hline \multirow[t]{7}{*}{ Other-methodology (7 projects) } & Decision and simulation modeling \\
\hline & $\begin{array}{l}\text { Examination of loss of information } \\
\text { related to outcome choice in meta- } \\
\text { analyses }\end{array}$ \\
\hline & $\begin{array}{l}\text { Indexing of SRDR projects (project } \\
\text { for the current study) }\end{array}$ \\
\hline & $\begin{array}{l}\text { Reliability of systematic reviews } \\
\text { addressing corneal diseases }\end{array}$ \\
\hline & $\begin{array}{l}\text { Summary of outcomes in clinical } \\
\text { trials addressing HIV/AIDS }\end{array}$ \\
\hline & $\begin{array}{l}\text { Summary of outcomes in clinical } \\
\text { trials in ophthalmology }\end{array}$ \\
\hline & $\begin{array}{l}\text { Summary of outcomes in } \\
\text { systematic reviews addressing } \\
\text { dry eye }\end{array}$ \\
\hline
\end{tabular}

\section{Abbreviations}

AHRQ: Agency for Healthcare Research and Quality; DAA: Data Abstraction Assistant; DOI: Digital object identifier; EPC: Evidence-based Practice Center; IPD: Individual patient data; IQR: Interquartile range; SRDR: Systematic Review Data Repository

\section{Acknowledgements}

This work is funded by the Agency of Healthcare Research and Quality (AHRQ), US Department of Health and Human Services under Contract No. HHSA290201500002I_HHSA29032012T, and prepared by the Brown Evidence-based Practice Center, Providence, Rhode Island, USA. Statements in this paper should not be construed as endorsement by the AHRQ or the US Department of Health and Human Services. The authors are grateful to Stephanie Chang, MD, MPH (Director, AHRQ EPC Program) and Lionel Bañez, MD (AHRQ Task Order Officer for SRDR) for their comments on previous versions of this manuscript. The authors are also grateful to others who have been involved with the development, advancement, and management of SRDR over the years, namely, Nira Hadar, PhD; Stanley Ip, MD; Birol Senturk,
BS; Byron Wallace, PhD; Manlik Kwong, BS; Christopher Parkin, MS; and Thomas Trikalinos, MD, PhD.

\section{Authors' contributions}

IJS conceived the idea for this paper. All authors provided input into the data elements that would need to be gathered. IJS and BTS extracted and adjudicated all data. IJS conducted all analyses and drafted the manuscript. All authors provided critical comments on the manuscript and have approved this version.

\section{Funding}

Agency of Healthcare Research and Quality

\section{Availability of data and materials}

The data gathered during this project are available publicly through https:// srdr.ahrq.gov/projects/1324.

\section{Ethics approval and consent to participate}

Not applicable

\section{Competing interests}

The authors declare that they developed and continue to maintain SRDR - the subject of this manuscript. The authors declare that they have no conflict of interest.

\section{Author details}

${ }^{1}$ Department of Health Services, Policy, and Practice, Center for Evidence Synthesis in Health, Brown University School of Public Health, 121 South Main Street, Box G-S121-8, Providence, RI 02903, USA. ²Department of Epidemiology, Center for Evidence Synthesis in Health, Brown University School of Public Health, 121 South Main Street, Box G-S121-8, Providence, RI 02903, USA. ${ }^{3}$ Department of Hygiene and Epidemiology, University of loannina School of Medicine, loannina, Greece.

Received: 29 March 2019 Accepted: 4 December 2019

Published online: 20 December 2019

\section{References}

1. Institute of Medicine. Finding what works in health care: standards for systematic reviews. Washington: The National Academies Presas; 2011.

2. Mayo-Wilson E, Fusco N, Li T, Hong H, Canner JK, Dickersin K. Multiple outcomes and analyses in clinical trials create challenges for interpretation and research synthesis. J Clin Epidemiol. 2017;86:39-50.

3. Mayo-Wilson E, Li T, Fusco N, Dickersin K. Practical guidance for using multiple data sources in systematic reviews and meta-analyses (with examples from the MUDS study). Res Synth Methods. 2018;9(1):2-12.

4. Ioannidis JP, Fanelli D, Dunne DD, Goodman SN. Meta-research: evaluation and improvement of research methods and practices. PLoS Biol. 2015; 13(10):e1002264

5. Wolfenden L, Grimshaw J, Williams CM, Yoong SL. Time to consider sharing data extracted from trials included in systematic reviews. Syst Rev. 2016;5(1): 185.

6. Schulz KF, Chalmers I, Hayes RJ, Altman DG. Empirical evidence of bias. Dimensions of methodological quality associated with estimates of treatment effects in controlled trials. JAMA. 1995;273(5):408-12.

7. Hannink G, Gooszen HG, Rovers MM. Comparison of registered and published primary outcomes in randomized clinical trials of surgical interventions. Ann Surg. 2013;257(5):818-23.

8. Ip S, Hadar N, Keefe $S$, et al. A web-based archive of systematic review data. Syst Rev. 2012;1:15.

9. Li T, Vedula SS, Hadar N, Parkin C, Lau J, Dickersin K. Innovations in data collection, management, and archiving for systematic reviews. Ann Intern Med. 2015;162(4):287-94

10. World Health Organization. International Statistical Classification of Diseases and Related Health Problems 10th Revision. 2016. https://icd.who.int/ browse10/2016/en. Accessed 19 Nov 2019.

11. Page MJ, Shamseer L, Altman DG, et al. Epidemiology and reporting characteristics of systematic reviews of biomedical research: a crosssectional study. PLoS Med. 2016;13(5):e1002028.

12. Page MJ, Shamseer $L$, Tricco AC. Registration of systematic reviews in PROSPERO: 30,000 records and counting. Syst Rev. 2018;7(1):32. 
13. Booth A, Clarke M, Ghersi D, Moher D, Petticrew M, Stewart L. An international registry of systematic-review protocols. Lancet (London, England). 2011;377(9760):108-9.

14. Stewart $L$, Moher $D$, Shekelle $P$. Why prospective registration of systematic reviews makes sense. Syst Rev. 2012;1:7.

15. Tricco AC, Lillie E, Zarin W, et al. A scoping review on the conduct and reporting of scoping reviews. BMC Med Res Methodol. 2016;16:15.

16. Elliott JH, Synnot A, Turner T, et al. Living systematic review: 1. Introductionthe why, what, when, and how. J Clin Epidemiol. 2017;91:23-30.

17. Abou-Setta AM, Jeyaraman MM, Attia A, et al. Methods for developing evidence reviews in short periods of time: a scoping review. PLoS One. 2016;11(12):e0165903.

18. Taichman DB, Backus J, Baethge C, et al. Sharing clinical trial data: a proposal from the International Committee of Medical Journal Editors. Rev Med Chil. 2016;144(1):11-3.

19. Ioannidis JP. The mass production of redundant, misleading, and conflicted systematic reviews and meta-analyses. Milbank Q. 2016;94(3):485-514.

20. Bashir R, Surian D, Dunn AG. Time-to-update of systematic reviews relative to the availability of new evidence. Syst Rev. 2018;7(1):195.

21. Jonnalagadda SR, Goyal P, Huffman MD. Automating data extraction in systematic reviews: a systematic review. Syst Rev. 2015;4:78.

22. O'Connor AM, Tsafnat G, Gilbert SB, Thayer KA, Wolfe MS. Moving toward the automation of the systematic review process: a summary of discussions at the second meeting of International Collaboration for the Automation of Systematic Reviews (ICASR). Sys Rev. 2018;7(1):3.

23. van Altena AJ, Spijker R, Olabarriaga SD. Usage of automation tools in systematic reviews. Res Synth Methods. 2019;10(1):72-82.

24. Lau J. Editorial: systematic review automation thematic series. Syst Rev. 2019:8(1):70

25. Tudur Smith C, Dwan K, Altman DG, Clarke M, Riley R, Williamson PR. Sharing individual participant data from clinical trials: an opinion survey regarding the establishment of a central repository. PLoS One. 2014;9(5): e97886.

26. Saldanha IJ, Schmid CH, Lau J, et al. Evaluating Data Abstraction Assistant, a novel software application for data abstraction during systematic reviews: protocol for a randomized controlled trial. Syst Rev. 2016;5(1):196.

27. Jap J, Saldanha IJ, Smith BT, Lau J, Li T. Response to 'Increasing value and reducing waste in data extraction for systematic reviews: tracking data in data extraction forms'. Syst Rev. 2018;7(1):18.

28. Jap J, Saldanha IJ, Smith BT, Lau J, Schmid CH, Li T, Data Abstraction Assistant Investigators. Features and functioning of Data Abstraction Assistant, a software application for data abstraction during systematic reviews. Res Synth Methods. 2019;10(1):2-14 PubMed ID: 30325115. https:// doi.org/10.1002/jrsm.1326.

29. Dahabreh IJ, Trikalinos TA, Balk EM, Wong JB. AHRQ methods for effective health care guidance for the conduct and reporting of modeling and simulation studies in the context of health technology assessment. In: Methods Guide for Effectiveness and Comparative Effectiveness Reviews. Rockville: Agency for Healthcare Research and Quality (US); 2008

30. Saldanha IJ, Li T, Yang C, Ugarte-Gil C, Rutherford GW, Dickersin K. Social network analysis identified central outcomes for core outcome sets using systematic reviews of HIV/AIDS. J Clin Epidemiol. 2016;70:164-75.

31. Saldanha IJ, Lindsley K, Do DV, et al. Comparison of clinical trial and systematic review outcomes for the 4 most prevalent eye diseases. JAMA Ophthalmol. 2017;135(9):933-40.

32. Saldanha IJ, Lindsley KB, Lum F, Dickersin K, Li T. Reliability of the evidence addressing treatment of corneal diseases: a summary of systematic reviews. JAMA Ophthalmol. 2019;137(7):775-85.

33. Saldanha IJ, Petris R, Han G, Dickersin K, Akpek EK. Research questions and outcomes prioritized by patients with dry eye. JAMA Ophthalmol. 2018; 136(10):1170-9.

34. Saldanha IJ, Lindsley K, Money S, Kimmel HJ, Smith BT, Dickersin K. Outcome choice and definition in systematic reviews leads to few eligible studies included in meta-analyses: a case study. (Submitted).

35. Li T, Saldanha IJ, Jap J, et al. A randomized trial provided new evidence on the accuracy and efficiency of traditional vs electronically annotated abstraction approaches in systematic reviews. J Clin Epidemiol. 2019;115:77-89.

36. Saldanha IJ, Senturk B, Smith BT, Robinson KA. Pilot to promote entry of structured data into the systematic review data repository: methods research report. Vol AHRQ publication no. 19-EH028-EF. Rockville: Agency for Healthcare Research and Quality; 2019.

37. Tsujimoto $Y$, Tsutsumi $Y$, Kataoka Y, et al. Statistical significance did not affect time to publication in non-Cochrane systematic reviews: a metaepidemiological study. J Clin Epidemiol. 2019;115:25-34.

\section{Publisher's Note}

Springer Nature remains neutral with regard to jurisdictional claims in published maps and institutional affiliations.
Ready to submit your research? Choose BMC and benefit from:

- fast, convenient online submission

- thorough peer review by experienced researchers in your field

- rapid publication on acceptance

- support for research data, including large and complex data types

- gold Open Access which fosters wider collaboration and increased citations

- maximum visibility for your research: over $100 \mathrm{M}$ website views per year

At BMC, research is always in progress.

Learn more biomedcentral.com/submissions 